\title{
Mathematical Study of the Effects of Temperature and Humidity on the Morphological Development of Pleurotus Eryngii Fruit Body
}

\author{
Juan Yang ${ }^{1}$, Jingyin Zhao ${ }^{1}$, Hailong $\mathrm{Yu}^{2}$, Yunsheng Wang ${ }^{1}$, \\ Ruijuan Wang ${ }^{2}$, and Lihua Tang ${ }^{2}$ \\ ${ }^{1}$ Technology \& Engineering Research Center for Digital Agriculture, \\ Shanghai Academy of Agricultural Sciences Shanghai 201423, P.R. China \\ yangjuan@saas.sh.cn \\ ${ }^{2}$ Institute of Edible Fungi, Shanghai Academy of Agricultural Sciences Shanghai 201423, \\ P.R. China
}

\begin{abstract}
The king oyster mushroom (Pleurotus eryngii) is one of the most popular mushrooms in Asia, Europe and North America. Its growth is influenced by environmental conditions, particularly air temperature and humidity. Using traditional methods of cultivation in plastic greenhouses, P. eryngii can be grown only in spring and autumn. However, mass cultivation using modern commercial methods is unrestricted by season, but precise environmental control is crucial, as the process is costly and a high energy consumption. Through experimentation and analysis of the effects of variations in air temperature and relative air humidity on morphological development, a mathematical model for these effects was developed. This model can be used to predict the optimal ranges of air temperature and humidity for various indices of morphological development of the fruiting body, and to guide commercial production. Using the model, standard values of morphological development, optimal environmental control ranges for each day of the fruiting body growth period were calculated. These values provide a reference suitable for application to actual production.
\end{abstract}

Keywords: Fruit body, morphology, air temperature, relative humidity, mathematical model, Pleurotus eryngii.

\section{Introduction}

Mushrooms are known for their nutritional and medicinal value, and the diversity of their bioactive components[1]. These organisms have long been valued as highly tasty and nutritious foods by many societies throughout the world. Among the edible mushrooms, the king oyster mushroom (Pleurotus eryngii) is one of the most popular in Asia, Europe and North America[2]. P. eryngii has several bioactive components, such as $\beta$-glucan[3] and ribonuclease[4], which have been isolated from the fruiting bodies of edible mushrooms. However, the fresh fruiting bodies are mainly used as a food sources. In Japan, production increased from $60 \mathrm{t}$ in 1995 to over 29,000 $\mathrm{t}$ in 
2003[5]. Even greater increases in production have occurred in China, where commercial production began in the late 1990s. Chinese growers produced an estimated $7300 \mathrm{t}$ in 2001, and $114,100 \mathrm{t}$ in 2003[6-7]. In the US, commercial production began in 2000 and has reached $85 \mathrm{t}$ by 2004[8].

As a commodity, the ideal morphology of the $P$. eryngii fruit body is generally columniform. The cap is smaller than that of the natural state, and can even be smaller than the stipe. Air environment seems to be very important for induction of fruiting body formation. The appropriate air environment is not only crucial for production, but also influences the ideal morphology. When air temperature and humidity are lower than optimal, the fruiting body does not growth, and can even wilt and die. Conversely, when air temperature and humidity are higher than optimal, the fruiting body grows quickly, but a higher proportion of anamorphic fruiting body.

Most studies focusing on the relationship between fungal growth and air environment have been qualitative, because of the large range of the environmental control variables in conditions of traditional cultivation in plastic greenhouses. In modern methods of mass commercial cultivation of $P$. eryngii, air environment is monitored through air temperature and relative humidity probes placed in the cultivation room. Air temperature and humidity are then adjusted in real time through air conditioning, humidifiers and fans controlled by a dedicated computer. Environmental control is thus very precise. Accurate environmental control can reduce the overall costs through increased yield.

The objective of this research, therefore, was to analyze the effect of different air temperatures and relative humidity on the morphological growth of the P. eryngii fruiting body, through experimental methods. A mathematical model for the effects of air temperature and humidity on growth was then established. Using the model, the appropriate environmental ranges for morphological growth of $P$. eryngii in commercial production were obtained. Finally, the model could make useful predictions about air environment variables to guide environmental control in the commercial production of $P$. eryngii.

\section{Materials and Methods}

\subsection{Experiments}

In this study, the air climate control in the growing rooms was designed and manufactured by Patron AEM; temperature, humidity and $\mathrm{CO}_{2}$ concentrations in the growing rooms could be controlled very precisely and efficiently. There were two treatments. The first was with air temperatures of $14^{\circ} \mathrm{C}, 15^{\circ} \mathrm{C}, 16^{\circ} \mathrm{C}, 17^{\circ} \mathrm{C}$ and $18^{\circ} \mathrm{C}$. The second was with relative humidity of $89 \%, 91 \%, 93 \%, 95 \%$ and $97 \%$. The intensity of illumination in the growing room was 500-1000Lx. The experiment was a 2 (supplement) $\times 5$ (treatment) design with three replicates per treatment. Morphological growth indicators were measured daily (every $24 \mathrm{~h}$ ), with 8 bottles for each experiment. Each value is the mean of 24 measured results $(3$ replicates $\times 8$ bottles). 
The morphological growth is characterized by three indicators: first, cap diameter, which reflects the size of the circular cap of fruiting body; second, stipe diameter, which is measured at the base and reflects the approximate size of the columniform stipe of the fruiting body; and third, stipe height, which is measured from the base of the stipe to the cap. Each day, two or three of the bigger fruit bodies in each cultivated bottle of eight examples were measured by vernier caliper.

\subsection{Model Validation}

To validate the model the three morphological growth indicators described above were computed with the model and then compared with field data. The following three indices were computed under two situations to assess the closeness of the estimated data to the measured values: correlation coefficient $(R)$, bias (Bias)[9], root mean square error $(R M S E)[10]$, and the percent root mean square error $(\%$ RMSE)[11].

$$
\begin{aligned}
\text { Bias } & =\frac{1}{n} \sum\left|O B S_{i}-S_{i}\right| \\
R M S E & =\sqrt{\frac{\sum_{i=1}^{n}\left(O B S_{i}-S I M_{i}\right)^{2}}{n}} \\
\% R M S E & =R M S E \times 100 /\left(\frac{1}{n} \sum O B S_{i}\right)
\end{aligned}
$$

$O B S_{i}$ and $S I M_{i}$ are the measured and simulated value, respectively, for the $i$ th data point of $n$ observations.

\section{Results}

During the growth period of the fruiting body, the three morphological growth indices of $P$. eryngii showed significant changes over different days (Table 1). We found that the optimal air temperature and humidity facilitated cap expansion, stipe heightening and thickening. For any single growth indicator, the optimal air temperature and humidity was different on each day (Table 2). Multiple statistical comparisons (Table 2) showed that over five days of growth, the optimal air temperature was $16^{\circ} \mathrm{C}, 17^{\circ} \mathrm{C}$ and $18^{\circ} \mathrm{C}$ in the first three days, and $17^{\circ} \mathrm{C}$ or $18^{\circ} \mathrm{C}$, and $16^{\circ} \mathrm{C}$ for the last two days. Variation in air relative humidity over a range of $89-$ $97 \%$ did not significantly affect morphological growth of the fruiting body in these experiments (Table 2), but comparatively, the optimum relative humidity was $97 \%$, followed by $95 \%$ and $93 \%$. 
Table 1. The values of morphological growth indices of $P$. eryngii on each day.

\begin{tabular}{|c|c|c|c|c|c|}
\hline Indices Time/d & 1 & 2 & 3 & 4 & 5 \\
\hline Cap diameter & $0.729^{\mathrm{a}}$ & $1.164^{\mathrm{b}}$ & $1.890^{\mathrm{c}}$ & $2.922^{\mathrm{d}}$ & $4.041^{\mathrm{e}}$ \\
\hline Stipe height & $1.540^{\mathrm{a}}$ & $2.415^{\mathrm{b}}$ & $3.608^{\mathrm{c}}$ & $4.774^{\mathrm{d}}$ & $5.825^{\mathrm{e}}$ \\
\hline Stipe diameter & $1.170^{\mathrm{a}}$ & $1.433^{\mathrm{b}}$ & $1.881^{\mathrm{c}}$ & $2.347^{\mathrm{d}}$ & $2.639^{\mathrm{e}}$ \\
\hline
\end{tabular}

*The value of each index was each day's mean growth for both treatments. Different letters indicate statistically different values (ANOVA/LSD) $(\mathrm{P}<0.05)$.

Table 2. The multiple comparisons result showing the influence of different air temperatures and relative humidity levels on morphological growth of the fruiting body of $P$. eryngii on each day.

\begin{tabular}{lllll}
\hline & Time/d & Cap diameter & Stipe height & Stipe diameter \\
\hline Air & 1 & $18^{\circ} \mathrm{C}, 17^{\circ} \mathrm{C}, 16^{\circ} \mathrm{C}$ & $16^{\circ} \mathrm{C}, 17^{\circ} \mathrm{C}, 18^{\circ} \mathrm{C}$ & $16^{\circ} \mathrm{C}, 18^{\circ} \mathrm{C}, 17^{\circ} \mathrm{C}$ \\
temperature & 2 & $17^{\circ} \mathrm{C}, 16^{\circ} \mathrm{C}, 18^{\circ} \mathrm{C}$ & $16^{\circ} \mathrm{C}, 17^{\circ} \mathrm{C}, 18^{\circ} \mathrm{C}$ & $17^{\circ} \mathrm{C}, 18^{\circ} \mathrm{C}, 16^{\circ} \mathrm{C}$ \\
treatment & 3 & $17^{\circ} \mathrm{C}, 18^{\circ} \mathrm{C}$ & $18^{\circ} \mathrm{C}, 16^{\circ} \mathrm{C}$ & $16^{\circ} \mathrm{C}, 18^{\circ} \mathrm{C}, 17^{\circ} \mathrm{C}$ \\
& 4 & $17^{\circ} \mathrm{C}$ & $18^{\circ} \mathrm{C}$ & $16^{\circ} \mathrm{C}, 18^{\circ} \mathrm{C}$ \\
& 5 & $17^{\circ} \mathrm{C}$ & $18^{\circ} \mathrm{C}$ & $16^{\circ} \mathrm{C}$ \\
\hline Air relative & 1 & $97 \%, 95 \%, 91 \%$ & $93 \%, 89 \%, 95 \%$ & $97 \%, 95 \%, 89 \%$ \\
humidity & 2 & $97 \%, 95 \%, 91 \%$ & $93 \%, 97 \%, 91 \%$ & $93 \%, 91 \%, 97 \%$ \\
treatment & 3 & $97 \%, 89 \%, 93 \%$ & $93 \%, 97 \%, 89 \%$ & $93 \%, 89 \%, 91 \%$ \\
& 4 & $93 \%, 97 \%, 89 \%$ & $97 \%, 93 \%, 89 \%$ & $97 \%, 93 \%, 89 \%$ \\
& 5 & $97 \%, 91 \%$ & $97 \%, 93 \%, 91 \%$ & $97 \%, 93 \%$ \\
\hline
\end{tabular}

*The relative humidity/temperature was not considered in the air temperature/relative humidity treatment, and the effect of air temperature/relative humidity was analyzed on morphological growth.

*The former three air temperature and relative humidity conditions that showed no differences between them were listed in the table.

There is complexity and uncertainty in biological growth and $P$. eryngii is no exception. The optimal air temperature is independent of optimal relative humidity. For example, the optimum air temperature for stipe heightening is $18^{\circ} \mathrm{C}$, but at that temperature, $93 \%$ is not the only optimum relative humidity. Therefore, it is necessary to further analyze and confirm the optimal air environment.

The optimal air temperature for cap expansion is $17^{\circ} \mathrm{C}$ (Table 3) under relative humidity conditions of 93-97\% analyzed above. The optimal relative humidity for cap expansion is dependent on temperature (Table 3): $97 \%$ at $16^{\circ} \mathrm{C}$ and $18^{\circ} \mathrm{C}$, and $91-$ $97 \%$ at $17^{\circ} \mathrm{C}$. So the optimal air temperature and relative humidity conditions for cap expansion are $17^{\circ} \mathrm{C}$ and $97 \%$ respectively.

Under better relative humidity conditions of 93-97\%, the optimal air temperature for stipe heightening is $18^{\circ} \mathrm{C}$ at $93 \%$ and $97 \%$ relative humidity, and is $17^{\circ} \mathrm{C}$ and $18^{\circ} \mathrm{C}$ at $95 \%$ relative humidity. The optimal relative humidity for stipe heightening is 
also dependent on temperature (Table 3): $97 \%$ at $16^{\circ} \mathrm{C} ; 91 \%, 95 \%$ and $97 \%$ at $17^{\circ} \mathrm{C}$; $93 \%$ and $97 \%$ at $18^{\circ} \mathrm{C}$. So the optimal air temperature and relative humidity conditions for stipe heightening is $18^{\circ} \mathrm{C}$ and $97 \%$ relative humidity.

Under better relative humidity conditions of $93-97 \%$, the optimal air temperature for stipe thickening are $16^{\circ} \mathrm{C}$ and $17^{\circ} \mathrm{C}$ at $95 \%$ and $97 \%, 16^{\circ} \mathrm{C}$ and $18^{\circ} \mathrm{C}$ at $93 \%$ relative humidity. The optimal relative humidity for stipe thickening is also dependent on temperature (Table 3): $93 \%$ and $97 \%$ at $16^{\circ} \mathrm{C} ; 91 \%-95 \%$ at $17^{\circ} \mathrm{C} ; 97 \%$ at $18^{\circ} \mathrm{C}$. So the optimal air temperature and relative humidity conditions for stipe thickening is $16^{\circ} \mathrm{C}$ and $93 \%$ relative humidity.

Table 3. The results of multiple comparisons of influence of different air relative humidity/temperature treatment on fruiting body growth under specific air temperature/relative humidity conditions

\begin{tabular}{|c|c|c|c|c|c|c|c|c|c|}
\hline & $\# 1$ & $16^{\circ} \mathrm{C}$ & $17^{\circ} \mathrm{C}$ & $18^{\circ} \mathrm{C}$ & $\# 2$ & $91 \%$ & $93 \%$ & $95 \%$ & $97 \%$ \\
\hline Cap diameter & $\begin{array}{l}93 \% \\
95 \% \\
97 \%\end{array}$ & & $\begin{array}{l}\sqrt{ } \\
\sqrt{ } \\
\sqrt{ }\end{array}$ & & $\begin{array}{l}16^{\circ} \mathrm{C} \\
17^{\circ} \mathrm{C} \\
18^{\circ} \mathrm{C}\end{array}$ & $\sqrt{ }$ & $\sqrt{ }$ & $\sqrt{ }$ & $\begin{array}{l}\sqrt{ } \\
\sqrt{ } \\
\sqrt{ }\end{array}$ \\
\hline Stipe height & $\begin{array}{l}93 \% \\
95 \% \\
97 \% \\
\end{array}$ & & $\sqrt{ }$ & $\begin{array}{l}\sqrt{ } \\
\sqrt{ } \\
\sqrt{ }\end{array}$ & $\begin{array}{l}16^{\circ} \mathrm{C} \\
17^{\circ} \mathrm{C} \\
18^{\circ} \mathrm{C}\end{array}$ & $\sqrt{ }$ & $\sqrt{ }$ & $\sqrt{ }$ & $\begin{array}{l}\sqrt{ } \\
\sqrt{ } \\
\sqrt{ }\end{array}$ \\
\hline Stipe diameter & $\begin{array}{l}93 \% \\
95 \% \\
97 \%\end{array}$ & $\begin{array}{l}\sqrt{ } \\
\sqrt{ } \\
\sqrt{ }\end{array}$ & $\begin{array}{l}\sqrt{ } \\
\sqrt{ }\end{array}$ & $\sqrt{ }$ & $\begin{array}{l}16^{\circ} \mathrm{C} \\
17^{\circ} \mathrm{C} \\
18^{\circ} \mathrm{C}\end{array}$ & $\sqrt{ }$ & $\begin{array}{l}\sqrt{ } \\
\sqrt{ }\end{array}$ & $\sqrt{ }$ & $\begin{array}{l}\sqrt{ } \\
\sqrt{ }\end{array}$ \\
\hline
\end{tabular}

\#1 the optimum air temperature in temperature treatment under specific air relative humidity condition; \#2 the optimum air relative humidity in humidity treatment under specific air temperature condition. The air relative humidity/air temperature conditions that no difference for the morphology growth were marked by the symbol " $\sqrt{ }$ ".

Through comprehensive analysis of the data, we believe that the optimal air temperature and relative humidity conditions for morphological development of the fruiting body in the growing room is $16-18^{\circ} \mathrm{C}$ at a relative humidity of $93 \%$ and above. On different days, the optimal air temperature and relative humidity conditions for morphological development of the fruiting body are slightly different. In the appropriate range, lower air temperature and relative humidity are better for stipe thickening, higher air temperature and relative humidity are better for stipe heightening.

\section{$4 \quad$ Model Description}

\subsection{The Morphological Development Simulation Model}

\subsubsection{Effects of Air Temperature on Morphology Development (ETMD) Sub-model}

From the experimental results, the relationships between air temperature and cap diameter, or stipe diameter were single-peak curves; the relationship between air 
temperature and height of the stipe was a single-peak curve on the first day, and linear on the other days. Mathematically, the effects of air temperature on morphological development of the fruiting body can be presented as follows:

$$
\begin{gathered}
D_{J G}=a_{11} \cdot T^{2}+b_{11} \cdot T+c_{11} \\
L_{J B}= \begin{cases}a_{21} \cdot T^{2}+b_{21} \cdot T+c_{21} & t=1 \\
u_{1} \cdot T+k_{1} & t>1\end{cases} \\
D_{J B}=a_{31} \cdot T^{2}+b_{31} \cdot T+c_{31}
\end{gathered}
$$

where $D_{J G}$ is cap diameter, $L_{J B}$ is stipe height, $D_{J B}$ is stipe diameter, $T$ is air temperature $\left(14-18^{\circ} \mathrm{C}\right), a_{11}, b_{11}, c_{11}, a_{21}, b_{21}, c_{21}, a_{31}, b_{31}, c_{31}, u_{1}$ and $k_{1}$ are parameters, $t$ is time (1-5 days).

With values of $T, D_{J G}, L_{J B}$ and $D_{J B}$ measured experimentally, $a_{11}, b_{11}, c_{11}, a_{21}, b_{21}$, $c_{21}, a_{31}, b_{31}, c_{31}, u_{1}$ and $k_{1}$ were estimated through the nonlinear least squares method using Statistica 6.0. Because of the small effect of humidity observed experimentally on morphological development of the fruiting body, humidity was not considered in the parameters estimated. As there were substantial differences in the three growth indicators and temperature on different days of the fruiting body growth period, the parameters were estimated separately for each day (see Table 4) over five days.

Table 4. Estimated parameters in Eqs. (1) - (3)

\begin{tabular}{cccccccccc}
\hline Time/d & $a_{11}$ & $b_{11}$ & $c_{11}$ & $a_{21}$ & $b_{21} / u_{1}$ & $c_{21} / k_{1}$ & $a_{31}$ & $b_{31}$ & $c_{31}$ \\
\hline 1 & -0.02 & 0.76 & -5.84 & -0.03 & 0.87 & -5.69 & 0.02 & -0.56 & 4.69 \\
2 & -0.03 & 1.10 & -8.74 & & 0.27 & -1.93 & -0.02 & 0.80 & -6.02 \\
3 & -0.03 & 1.25 & -9.81 & & 0.42 & -3.02 & 0.02 & -0.40 & 3.68 \\
4 & -0.04 & 1.49 & -10.73 & & 0.47 & -2.64 & 0.02 & -0.50 & 4.78 \\
5 & -0.22 & 7.11 & -52.11 & & 0.46 & -1.57 & 0.06 & -1.78 & 16.08 \\
\hline
\end{tabular}

\subsubsection{Effects of Relative Humidity on Morphological Development (EHMD) Sub-model}

Although there was not significant observed effect of varying relative humidity on morphological development, air humidity is almost certainly an important environmental factor for the production of $P$. eryngii. Therefore the mathematical relationship between air humidity and morphological development was also simulated. From the results, the optimal air temperature for $P$. eryngii is $16^{\circ} \mathrm{C}$ and above. At temperatures of $16^{\circ} \mathrm{C}$ and higher, the morphological development of the fruiting body has the following mathematical relationship with relative humidity: 


$$
\begin{gathered}
D_{J G}=a_{12} \cdot H^{2}+b_{12} \cdot H+c_{12} \\
L_{J B}=u_{2} \cdot H+k_{2} \\
D_{J B}=a_{32} \cdot H^{2}+b_{32} \cdot H+c_{32}
\end{gathered}
$$

in which $H$ is relative humidity (89-97\%), $a_{12}, b_{12}, c_{12}, a_{32}, b_{32}, c_{32}, u_{2}$ and $k_{2}$ are parameters.

With the experimentally measured $H, D_{J G}, L_{J B}$ and $D_{J B}, a_{12}, b_{12}, c_{12}, a_{32}, b_{32}, c_{32}, u_{2}$ and $k_{2}$ were estimated using the same method as for the parameters in Eqs. (1) - (3). As there were substantial differences of morphological development indices on different days of fruiting body growth period, the parameters were estimated separately for each day (see Table 5) over five days.

Table 5. Estimated parameters in Eqs. (4) - (6)

\begin{tabular}{ccccccccc}
\hline Time/d & $a_{12}$ & $b_{12}$ & $c_{12}$ & $a_{32}$ & $b_{32}$ & $c_{32}$ & $u_{2}$ & $k_{2}$ \\
\hline 1 & -0.004 & 0.66 & -29.74 & -0.001 & 0.10 & -3.26 & 0.01 & 0.44 \\
2 & -0.01 & 1.78 & -81.63 & -0.002 & 0.40 & -17.12 & 0.09 & -5.65 \\
3 & -0.0003 & 0.05 & -0.69 & -0.002 & 0.43 & -17.81 & 0.10 & -4.74 \\
4 & -0.005 & 0.94 & -40.78 & -0.001 & 0.10 & -2.39 & 0.12 & -6.23 \\
5 & -0.02 & 3.68 & -166.35 & 0.004 & -0.69 & 34.34 & 0.09 & -2.41 \\
\hline
\end{tabular}

\subsection{Validation of the Morphological Development Simulation Model}

The morphological development simulation model was validated by assessing the correlation coefficient $(R)$, bias (Bias), root mean square error (RMSE) and the percent root mean square error (\%RMSE) for the measured and estimated values. The detailed results are shown in Table 6.

From the mathematical model, the effect of air temperature gave the following results: R, Bias, RMSE and \%RMSE were $88.6 \%, 0.325 \mathrm{~cm}, 0.335$ and $13.42 \%$, respectively, for cap diameter (Eq.1); 93.7\%, $0.226 \mathrm{~cm}, 0.305$ and $8.40 \%$, respectively, for stipe height (Eq.2); and $92.6 \%, 0.173 \mathrm{~cm}, 0.213$ and $10.09 \%$, respectively, for stipe diameter (Eq.3).

The effect of relative humidity resulted in the following:R, Bias, RMSE and $\%$ RMSE were $85.4 \%, 0.350 \mathrm{~cm}, 0.396$ and $17.42 \%$, respectively, for cap diameter (Eq.4); 91.7\%, $0.297 \mathrm{~cm}, 0.392$ and 9.84\%, respectively, for stipe height (Eq.5); $93.4 \%, 0.237 \mathrm{~cm}, 0.276$ and $19.97 \%$, respectively, for stipe diameter (Eq.6).

The estimated morphological development indices are correlated well with the measured values. This is also shown from Figures 1-3. 
Table 6. The values of validation indices for the morphological development simulation model

\begin{tabular}{clcccc}
\hline \multirow{2}{*}{ Model } & \multirow{2}{*}{ Index } & \multicolumn{4}{c}{ Model validation indexes } \\
\cline { 3 - 6 } & & $R^{2}$ & Bias /cm & RMSE & $\%$ RMSE \\
\hline \multirow{2}{*}{ ETMD } & Cap diameter & $88.6 \%$ & 0.325 & 0.335 & $13.42 \%$ \\
\multirow{2}{*}{ sub-model } & Stipe height & $93.7 \%$ & 0.226 & 0.305 & $8.40 \%$ \\
& Stipe diameter & $92.6 \%$ & 0.173 & 0.213 & $10.09 \%$ \\
\hline \multirow{2}{*}{ EHMD } & Cap diameter & $85.4 \%$ & 0.350 & 0.396 & $17.42 \%$ \\
\multirow{2}{*}{ sub-model } & Stipe height & $91.7 \%$ & 0.297 & 0.392 & $9.84 \%$ \\
& Stipe diameter & $93.4 \%$ & 0.237 & 0.276 & $19.97 \%$ \\
\hline
\end{tabular}
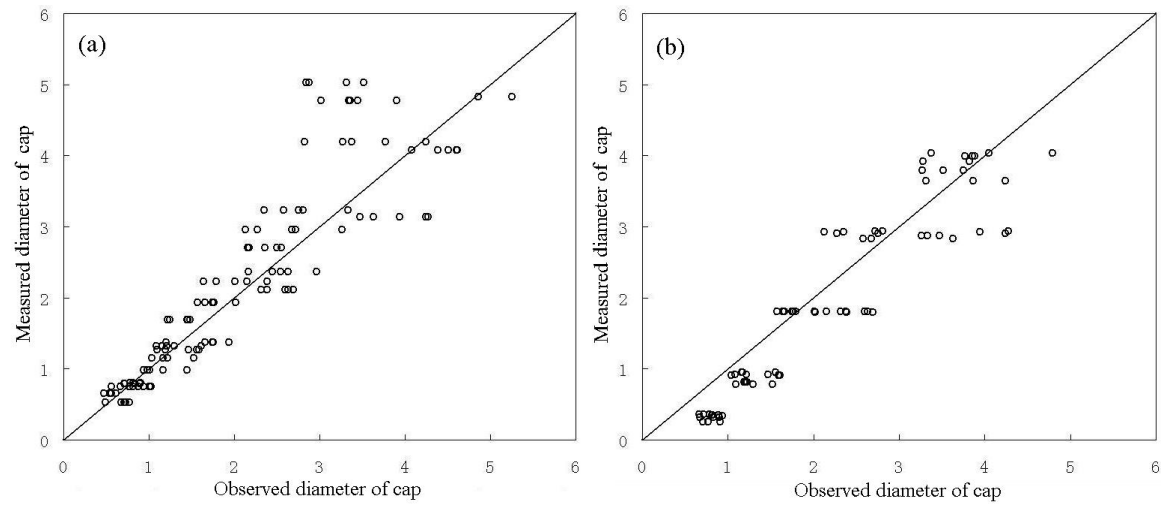

(a) Simulations using the effects of air temperature on the morphological development submodel (Eq. 1); (b) simulations using the effects of relative air humidity on the morphological development sub-model (Eq. 4). The dashed line (-) is the 1:1 line.

Fig. 1. Measured vs. simulated diameter of the cap
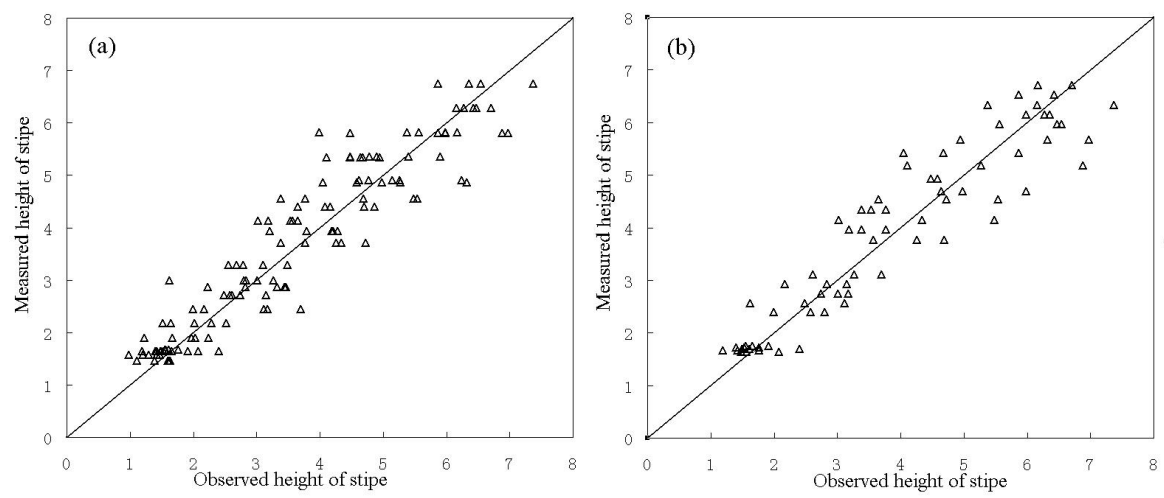

(a) Simulations using the effects of air temperature on morphological development sub-model (Eq. 2); (b) simulations using the effects of relative air relative humidity on the morphological development sub-model (Eq. 5). The dashed line (-) is the 1:1 line.

Fig. 2. Measured vs. simulated height of the stipe 

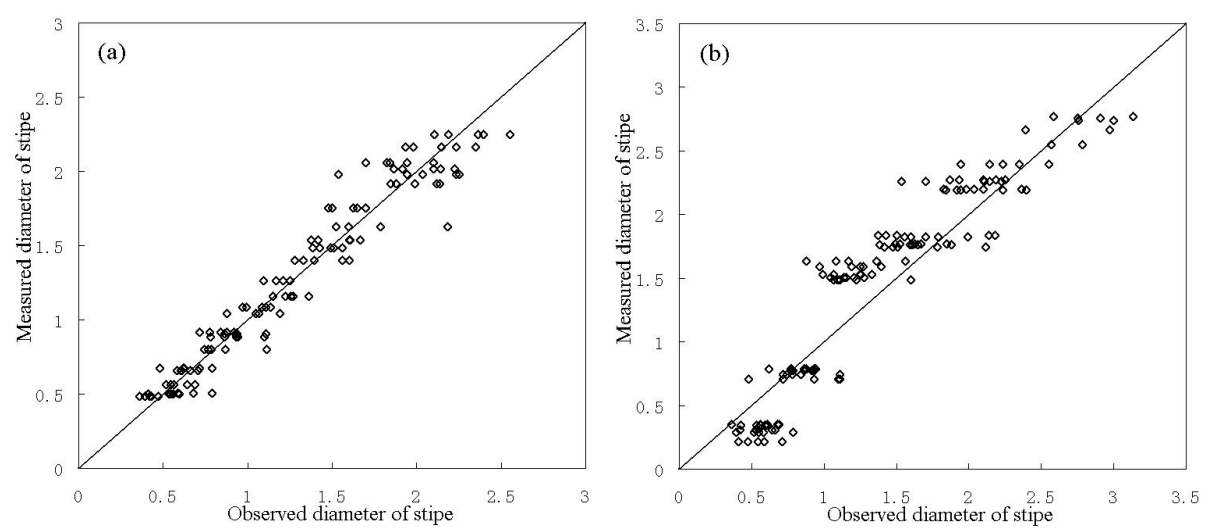

(a) Simulations using the effects of air temperature on the morphological development submodel (Eq. 3); (b) simulations using the effects of relative air humidity on the morphological development sub-model (Eq. 6). The dashed line (-) is the 1:1 line.

Fig. 3. Measured vs. simulated diameter of the stipe

\subsection{The Appropriate Environment Range Model for Morphological Development}

\subsubsection{The Appropriate Air Temperature Range Sub-model for Morphological Development}

From equations (1) - (3), we obtained the following formulas:

$$
\begin{aligned}
& T_{o p t-J G}=\left[\frac{-b_{11}-\sqrt{b_{11}{ }^{2}-4 a_{11}\left(c_{11}-S D_{J G}\right)}}{2 a_{11}}, \frac{-b_{11}+\sqrt{b_{11}{ }^{2}-4 a_{11}\left(c_{11}-S D_{J G}\right)}}{2 a_{11}}\right] \\
& T_{\text {opt }-L J B}=\left\{\begin{array}{l}
{\left[\frac{-b_{21}-\sqrt{b_{21}{ }^{2}-4 a_{21}\left(c_{21}-S L_{J B}\right)}}{2 a_{21}}, \frac{-b_{21}+\sqrt{b_{21}{ }^{2}-4 a_{21}\left(c_{21}-S L_{J B}\right)}}{2 a_{21}}\right]} \\
\left(S L_{J B}-k_{1}\right) / u_{1} \quad t>1
\end{array} \quad t=1\right. \\
& T_{o p t-D J B}=\left[\frac{-b_{31}-\sqrt{b_{31}{ }^{2}-4 a_{31}\left(c_{31}-S D_{J B}\right)}}{2 a_{31}}, \frac{-b_{31}+\sqrt{b_{31}{ }^{2}-4 a_{31}\left(c_{31}-S D_{J B}\right)}}{2 a_{31}}\right] \\
& T_{\text {opt }}=T_{o p t-J G} \cap T_{o p t-L J B} \cap T_{o p t-D J B}
\end{aligned}
$$

where $T_{\text {opt-DJG }}$ is the optimal air temperature for cap diameter, $T_{\text {opt-LJB }}$ is the optimal air temperature for stipe height, $T_{o p t-D J B}$ is the optimal air temperature for stipe diameter. $T_{\text {opt }}$ is the optimal air temperature for the fruiting body, which is the intersection of $T_{\text {opt-DJG}}, T_{\text {opt-LJB }}$ and $T_{\text {opt-DJB}} . S D_{J G}, S L_{J B}$ and $S D_{J B}$ are standard values of cap diameter, 
stipe height and stipe diameter on different days, and is taken from the average value of the indices in this study (see Table 7).

\subsubsection{The Appropriate Relative Humidity Range Sub-model for Morphological Development}

From equations (4) - (6), we obtained the following formulas:

$$
\begin{gathered}
H_{o p t-J G}=\left[\frac{-b_{12}-\sqrt{b_{12}{ }^{2}-4 a_{12}\left(c_{12}-S D_{J G}\right)}}{2 a_{12}}, \frac{-b_{12}+\sqrt{b_{12}{ }^{2}-4 a_{12}\left(c_{12}-S D_{J G}\right)}}{2 a_{12}}\right] \\
H_{o p t-L J B}=\left(S L_{J B}-k_{2}\right) / u_{2} \\
H_{o p t-D J B}=\left[\frac{-b_{32}-\sqrt{b_{32}{ }^{2}-4 a_{32}\left(c_{32}-S D_{J B}\right)}}{2 a_{32}}, \frac{-b_{32}+\sqrt{b_{32}{ }^{2}-4 a_{32}\left(c_{32}-S D_{J B}\right)}}{2 a_{32}}\right] \\
H_{o p t}=H_{o p t-J G} \cap H_{o p t-L J B} \cap H_{o p t-D J B}
\end{gathered}
$$

where $H_{\text {opt-DJG }}$ is the optimal relative humidity for cap diameter, $H_{\text {opt-LJB }}$ is the optimal relative humidity for stipe height, $H_{\text {opt-DJB }}$ is the optimal relative humidity for stipe diameter. $H_{o p t}$ is the optimal relative humidity for the fruiting body, which is the intersection of $H_{o p t-D J G}, H_{o p t-L J B}$ and $H_{o p t-D J B}$.

\subsubsection{Simulated Optimal Environmental Conditions for the Fruiting Body Growth Period}

Using equations (7) - (14), the optimal environmental control standards can be computed for each day of the fruiting body growth period (Table 7).

Table 7. The standard values of morphological development and the simulated optimal environment conditions in the fruiting body growth period

\begin{tabular}{cccccc}
\hline $\begin{array}{c}\text { Time } \\
/ \mathrm{d}\end{array}$ & $\begin{array}{c}S D_{J G} \\
/ \mathrm{cm}\end{array}$ & $\begin{array}{c}S L_{J B} \\
/ \mathrm{cm}\end{array}$ & $\begin{array}{c}S D_{J B} \\
/ \mathrm{cm}\end{array}$ & $\begin{array}{c}\text { Optimal } \\
\text { temperature range } \\
/{ }^{\circ} \mathrm{C}\end{array}$ & $\begin{array}{c}\text { Optimal humidity } \\
\text { range } / \%\end{array}$ \\
\hline 1 & 0.729 & 1.540 & 1.170 & {$[15.4,16.9]$} & {$[87,96]$} \\
2 & 1.164 & 2.415 & 1.433 & {$[15.9,19.1]$} & {$[89,95.4]$} \\
3 & 1.890 & 3.608 & 1.881 & {$[15.8,16.4]$} & {$[87,96]$} \\
4 & 2.922 & 4.774 & 2.347 & {$[15.8,16.4]$} & {$[91,96]$} \\
5 & 4.041 & 5.825 & 2.639 & {$[14.5,17.2]$} & {$[91,94]$} \\
\hline
\end{tabular}




\section{Conclusion}

When compared with traditional cultivation in plastic greenhouses, modern methods of commercial mass cultivation of fungi has the advantage of uniform growth, high efficiency and is unrestricted by season. However, production is costly and has high energy consumption. Therefore, optimal environmental control is crucial. Higher fungi are considered difficult to cultivate in the laboratory without complex growth medium[12] because of the limited growing space in a laboratory. Environmental control needs to be very precise in modern commercial production of fungi, and the application of the optimal climate control parameters is crucial for ideal fruiting body development, and therefore these study results have great practical significance. Using the simulation models morphological development rate and optimal climate control values can be obtained to guide the actual environmental control settings in the commercial production of $P$. eryngii.

In general, fungi are very difficult to study through experimental means alone because of the complexity of their natural growth habitat (e.g., soils) and the microscopic scale of growth (e.g., tip vesicle translocation and hyphal tip extension)[13]. Some research focus on shape is on the cell[14].Mathematical modeling provides a complementary, powerful and efficient method of investigation. The aim of mathematical modeling is to reduce a complex (biological) system into a simpler (mathematical) system that can be analyzed in far more detail and from which key properties can be identified[13].

Temporal effects were considered in the model. The parameters in the model varied for each day. The relationship between the indices of morphological development and air environment in this paper was represented by a quadratic equation with one variable, reflecting the experimental results which showed that the estimated optimal air temperature and relative humidity are not the highest values of appropriate air temperature and relative humidity. The calculated optimal air temperature and relative humidity values predicted by the model are different for each day. For this reason, environmental parameters should be varied daily in the commercial production of $P$. eryngii, and not set at temperatures of $16-18^{\circ} \mathrm{C}$ or $93 \%$ above relative humidity, as analyzed to be optimal by the experiments. This also illustrates the practical value of the model.

We conclude that our model described in this article provides a powerful tool to predict the morphological development rate according to air environment, and to guide real-time adjustment of air environment for commercial production of $P$. eryngii.

Acknowledgements. This work was supported by grants from the National Natural Science Foundation of China (No. 30800765) and the Project of the Science and Technology Commission of Shanghai Municipality, China (Nos. 08DZ2210600 and 08QA14058). Carbohydr. Polym. 


\section{References}

1. Ng, T.B.: A review of research on the protein-bound polysaccharide (polysaccharopeptide, PSP) from the mushroom Coriolus versicolor (Basidiomycetes: Polyporaceae). Gen. Pharmacol. 30, 1-4 (1998)

2. Rodriguez Estrada, A.E., Royse, D.J.: Yield, size and bacterial blotch resistance of Pleurotus eryngii grown on cottonseed hulls/oak sawdust supplemented with manganese, copper and whole ground soybean. Bioresour. Technol. 98, 1898-1906 (2007)

3. Carbonero, E.R., Gracher, A.H.P., Smiderle, F.R., et al.: A $\beta$-glucan from the fruit bodies of edible mushrooms Pleurotus eryngii and Pleurotus ostreatoroseus. Carbohydr. Polym. 66, 252-257 (2006)

4. Ng, T.B., Wang, H.X.: A novel ribonuclease from fruiting bodies of the common edible mushroom Pleurotus eryngii. Peptides 25, 1365-1368 (2004)

5. Yamanaka, K.: Cultivation of new mushroom species in East Asia. In: Tan, et al. (eds.) Proceedings of the Fifth International Conference on Mushroom Biology and Mushroom Products, Shanghai, China, April 8-12; Acta Edulis Fungi 12 (suppl.), 343-349 (2005)

6. Chang, S.T.: Witnessing the development of the mushroom industry in China. In: Tan, et al. (eds.) Proceedings of the Fifth International Conference on Mushroom Biology and Mushroom Products, Shanghai, China, April 8-12; Acta Edulis Fungi 12 (suppl.), 3-19 (2005)

7. Tan, Q., Wang, Z., Cheng, J., Guo, Q., Guo, L.: Cultivation of Pleurotus spp. in China. In: Tan, et al. (eds.) Proceedings of the Fifth International Conference on Mushroom Biology and Mushroom Products, Shanghai, China, April 8-12; Acta Edulis Fungi 12 (suppl.), 338349 (2005)

8. Royse, D.J., Shen, Q., McGarvey, C.: Consumption and production of recently domesticated edible fungi in the United States with a projection of their potential. In: Tan, et al. (eds.) Proceedings of the Fifth International Conference on Mushroom Biology and Mushroom Products, Shanghai, China, April 8-12; Acta Edulis Fungi 12 (suppl.), 331-337 (2005)

9. Kobayashi, K., Salam, M.U.: Comparing simulated and measured values using mean squared deviation and its components. Agron. J. 92, 345-352 (2000)

10. Moreno-Sotomayora, A., Weiss, A.: Improvements in the simulation of kernel number and grain yield in CERES-Wheat. Field Crops Res. 88, 157-169 (2004)

11. Jansen, P.H.M., Heuberger, P.S.C.: Calibration of process-oriented models. Ecol. Model 83, 55-66 (1993)

12. Bazała, M.A.: Transport of radiocesium in mycelium and its translocation to fruitbodies of a saprophytic macromycete. Environ. Radioact., 1-3 (2008)

13. Boswell, G.P., Jacobs, H., Gadd, G.M., et al.: A mathematical approach to studying fungal mycelia. Mycologist 17, 165-171 (2003)

14. Braaksma, A., van Doorn, A.A., Kieft, H., et al.: Morphometric analysis of ageing mushrooms (Agaricus bisporus) during postharvest development. Postharvest Bio. Tech. 13, 71-79 (1998) 